\title{
LOS TEATROS FIJOS DE BADAJOZ EN EL SIGLO XVII
}

Fernando Marcos Álvarez

Las noticias que tenemos sobre teatros fijos en Badajoz durante el siglo XVII son muy escasas y, hasta 1669 en que se contrata la obra del corral de los hospitales, siempre fortuitas. Esta pobreza nos resulta paradojica dada la continua presencia en la ciudad de compañías de comedias, hecho del que disponemos de abundantes testimonios, y dada también la certidumbre de representaciones en esos locales por la garantía de las siguientes citas: El 24 de julio de 1626 el autor Lorenzo Hurtado de la Cámara salda una deuda de quinientos reales ${ }^{1}$ con lo procedido «de hacer en el patio una comedia (...) con los demás sus compañeros». El 9 de enero de 1658, y con la intención de festejar el nacimiento del príncipe Felipe Próspero (1657), el municipio contrata a la compañía de Miguel de Orozco ${ }^{2}$ para que hiciera en la plaza pública cuatro comedias

Siglas utilizadas:

$A C B$, Archivo de la Catedral de Badajoz.

$A D P B$, Archivo de la Diputación Provincial de Badajoz.

$A H P B$, Archivo Histórico Provincial de Badajoz.

$A M B$, Archivo Municipal de Badajoz.

l.a., libro de acuerdos.

1 Los debía a la cofradía del Santísimo Sacramento (AHPB, prt. 254, f. 195 vto.).

$2 A H P B$, prt. 229, f. 11. Es curiosa esta cita por la dejadez que hacía el consistorio, y aun más su alcalde mayor, en el cumplimiento de las disposiciones reales referidas al teatro: desde 1615 estaba prohibido representar en domingo. 
con sus sainetes y loas, "y es declaración expresa -concluye la escrituraque dichas cuatro comedias se han de hacer primero en el patio, cobrando la entrada dicha compañía». En 1664 el obispo don Jerónimo Rodríguez Valderas redacta y promulga las Constituciones que se han de guardar en el colegio seminario de esta ciudad de Badajoz ${ }^{3}$; pues bien, en su «Título XVI. En qué forma han de salir los colegiales y a qué partes», se conmina a los estudiantes a que «no entren en los lugares públicos a oír ni ver comedias, ni otras representaciones de este género, pena de un mes de prisión». En el ayuntamiento del 15 de julio de 1669 el alcalde mayor del consistorio y otros ediles se lamentan del desdoro que el día anterior, domingo, sufrieron sus personas cuando acudieron a ver representar a la compañía de Francisco Gutiérrez, ya que «por ser una de las de más opinión (...), y haber ocurrido en el patio de comedias numeroso concurso de gente (...), los caballeros regidores que asisten a ver las comedias no tienen lugar decente ni están con la decencia que conviene». Ante esta denuncia ${ }^{4}$, y para evitar que en lo sucesivo se repitiera el oprobio, acordó el pleno que «en el dicho patio, en lugar decente, se haga un tablado y en él se pongan los asientos necesarios para que el regimiento vea las dichas comedias».

Los pasajes anteriores prueban la existencia de locales destinados al teatro comercial, pero ¿dónde estaban en la primera mitad del siglo XVII? Hasta ahora sólo hemos conseguido localizar dos. Uno de ellos, el más antiguo ${ }^{5}$, se encontraba en las casas que fueron de Juan Bravo de Jerez, y en él, el 22 de junio de 1611, Alonso de Escobar dio muerte en una reyerta a Diego Díaz de Miranda, vecino de $\mathrm{Haro}^{6}$. Sin embargo, resulta difícil situarlo en la dilatada superficie de esa mansión cuyo perímetro en planta lo delimitaban cuatro calles distintas. Un contrato de arrendamiento ${ }^{7}$ fechado el 16 de mayo de 1619 puede que aclare ese dato. En él se lee que Bartolomé Sánchez de Aldana, administrador de los bienes de don Pedro Ibáñez y de doña Isabel de Leguizamón, su mujer, cede por tres años a Jerónimo Sánchez de Hoces un corral «en las casas que dicen de Leguizamón (...), el cual linda con el de la Rebolla y con el corral que tiene dicha casa que llaman el patio, y con dos callejas». Las casas que menciona el texto, cuya propiedad disfrutaba la familia Ibáñez de Leguizamón desde

3 Archivo del Seminario Diocesano, const., fs. 67-97.

$4 A M B$, l.a. n. 12 , f. 72 vto.

5 En la p. 380 del vol. I de las Memorias de la Real Academia de Extremadura de las Letras y las Artes (Trujillo, 1983), se cita de modo impreciso la existencia de este corral, y se anota el año de 1592 como fecha de su construcción apoyándose en información aportada por Mariano Grau en «El teatro en Segovia» (Estudios segovianos, $X$, 1958). El confer es erróneo pues revisado ese artículo (pp. 5-97 del n. ${ }^{2}$ 28-29) no hemos hallado en él ninguna alusión a teatros de Badajoz.

6 AHPB, prt. 153, s.f., 6 de agosto 1613.

${ }^{7} A H P B$, prt. 1782, s.f. 
finales del siglo XVI, fueron antes de Juan Bravo de Jerez ${ }^{8}$; el «corral que llaman el patio" es muy posible que fuera el sitio de las comedias, y esto por ser el término patio el apelativo más utilizado en Badajoz para nombrarlo ${ }^{9}$, y el que se diga que el otro lindero lo marcaba el corral de la Rebolla nos permite emplazarlo en la acera izquierda de la actual calle de De Gabriel, entre las de Menacho y Santo Domingo ${ }^{10}$. Si ese viejo teatro estaba a la intemperie, y parece ser que sí, sus instalaciones serían las básicas del corral castellano: un escenario protegido del sol y de la lluvia por un pequeño tejadillo, una zona descubierta para los espectadores masculinos y unos cobertizos adosados a las tapias laterales del tablado con la cazuela y los asientos preferentes ${ }^{11}$. Ignoramos el tiempo que se mantuvo en servicio, pero cuando en 1630 Sebastián Montero de Espinosa compró la vivienda «con todas las plazas y sitios anejos» a don Pedro Ibáñez de Leguizamón, ese recinto no aparece mencionado en la carta de venta ${ }^{12}$.

El otro teatro se documenta en un poder ${ }^{13}$ otorgado el 19 de septiembre de 1648 por doña Inés de Fonseca. Esta señora, viuda del regidor Pedro García Rico y administradora del mayorazgo que fundo su hermano don García Laso de

8 El edificio lo mandó construir don Francisco de Figueroa. A mediados del siglo XVI se lo compro Juan Bravo de Jerez, alcalde mayor de sacas, y alli vivía en 1553. Al morir este señor lo heredo su hijo don Antonio Bravo de Jerez, quien, hacia 1585, fue desposeído judicialmente de su propiedad por no haber liberado de don Pedro Ibáñez un fuerte censo que lo gravaba (Archivo del Convento de Ntra. Sra. de la Merced, carpeta de varios).

9 En la vasta documentación que tenemos recogida sobre el teatro en Badajoz, patio aparece con una frecuencia del $65,3 \%$, corral con la del $32,4 \%$ y casa de comedias con la del $2,3 \%$.

10 Catalina Rodríguez, la Rebolla, poseía una casa con su corral en la esquina de la calle de De Gabriel - de la Rebolla en el siglo XVII- con la de Santo Domingo. Un estrecho callejón la aislaba de la propiedad de Juan Bravo de Jerez.

11 Esta estructura rudimentaria fue la que tuvo el madrileño corral de Valdivieso, levantado en 1579 (OTHón ARRóniz, Teatros y escenarios del Siglo de Oro, Madrid, 1977, p. 58). Es muy probable que la calleja izquierda de las dos que limitaban el corral que arrendo Jerónimo Sánchez de Hoces, sirviera para acceder al teatro. En tal caso el tablado habría que situarlo en la fachada trasera de la vivienda, localización que permitiría usar sus vanos de luces y vistas para las escenas de «lo alto del teatro» (vid. J.E. VAREY, Cosmovisión y escenografia: El teatro español en el Siglo de Oro, Madrid, 1987, p. 209).

12 La escritura se otorgó en Madrid el 19 de julio de 1630 ante el escribano Santiago Fernández. La descripción de la propiedad dice que tras el cuerpo de vivienda, cuya fachada principal daba a la calle de San Onofre, había un amplísimo espacio con cerca a tres calles - De Gabriel, Santo Domingo y la hoy desaparecida Travesía de las Monjas--, donde se encontraba un jardín, una huerta con arbolado - higueras y granados - y un pozo con una noria. La misma reseña de la finca es la que se hace en 1674 cuando las clarisas descalzas establecieron en ella su convento (cfr. nota n. ${ }^{9} 8$ ).

13 AHPB, prt. 1464, f. 224. 
Figueroa, relaciona en esa escritura los bienes del vínculo que estaban arrendados o censuados, $y$ entre ellos incluye unas casas principales en la calle de Gonzalo de Hoces, esquina con la plaza de Juan de Fonseca ${ }^{14}$, «que son las casas que tienen el Patio a la entrada». Suponemos que en este caso, vista la topografía de la manzana en planos de la época, el local debería de ser un amplio salón habilitado para ese empleo.

En fecha no determinada de 1629 don Alonso de Toledo y Mendoza, marqués de Villamagna, a la sazón corregidor de Badajoz, propuso al consistorio de la ciudad la construcción de un patio de comedias en un solar que había en la calle de San Onofre, a mano izquierda, y que frontero a la casa que fue de Juan Bravo de Jerez, servía de plazuela para adorno de su fachada ${ }^{15}$. El ayuntamiento en pleno hizo suya la sugerencia ${ }^{16}$ porque de ello «se le seguía mucha autoridad y útil para sus propios», pregonó el acuerdo, aceptó un proyecto y dispuso el comienzo inmediato de la obra. Como la superficie de terreno disponible era insuficiente, se amplía con la compra de parte de los corrales linderos y se derriba la tapia que los cercaba. A finales de ese año, cuando ya se se habían sacado los cimientos e invertido en la fábrica más de 11.000 reales, tuvo que interrumpirse el trabajo por no disponer el municipio de hacienda suficiente con que proseguirlo. Para lograr fondos el concejo solicita de Felipe IV licencia para aplicar a la obra 16.000 ducados de los arbitrios reales sobre baldíos, gracia que le fue concedida el 20 de diciembre ${ }^{17}$ con nota de que ese dinero se utilizara exclusivamente para «acabar, y acabéis, de labrar el dicho corral de comedias que tenéis en esa dicha ciudad, gastando en él lo que fuere necesario hasta ponerlo en toda perfección». El asentimiento del monarca se conoció en el cabildo del 20 de abril de 1630, y cinco meses después, el 30 de septiembre, se comisionó al alférez mayor don Francisco Becerra y al regidor don Gonzalo de Hoces para que se ocuparan del adelanto y conclusión del teatro ${ }^{18}$, encargos que no pudieron llevar a efecto por haber reclamado don Pedro de Segovia Ibá-

14 La calle de Gonzalo de Hoces es la actual de Ntra. Sra. de la Soledad, y la plaza de Juan de Fonseca, la plazuela dedicada a la misma advocación.

15 No podemos precisar la fecha exacta de la propuesta del marqués de Villamagna, que por cierto vivía en esa mansión, ni tampoco las de las inmediatas resoluciones del municipio por haberse perdido los libros de acuerdos del cabildo de los años 1628 y 1629. Las citas que hacemos proceden de fuentes posteriores, aunque muy cercanas. El sitio de las casas de Juan Bravo lo ocupa actualmente el Convento de las Descalzas.

16 AMB, l.a. n. 9 , f. 197.

$17 A M B$, l.a. n..$^{9} 4$, f. 83.

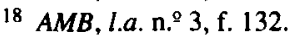


ñez de Leguizamón ${ }^{19}$ la reversión del solar a su dominio, y por haberse sacado los cimientos ${ }^{20}$ «estrechos y no del grosor y anchura requerido». El municipio desestimó la pretensión de don Pedro por tener por suyo todo el suelo urbano ${ }^{21}$, del que «siempre que hizo merced de solares para poblar y edificar, fue con calidad de que en cayéndose las casas o no teniéndolas reparadas quedasen los tales solares para esta ciudad, por manera que todos los dichos sitios en que han faltado edificios son de esta dicha ciudad», derecho foral que justificaba la afectación que se recurría ${ }^{22}$. Como, por otra parte, era sencillo y no muy caro el reparar y consolidar la cimentación, el ayuntamiento del 20 de agosto de 1632 decide «que la obra de la casa de comedias se prosiga y acabe», y nombra delegados para que «bien en pregón o como les pareciere» se encargaran de que se cumpliera el acuerdo ${ }^{23}$. Pero tampoco ahora se pudo realizar el empeño: El 26 de agosto de 1633 al acaudalado e influyente regidor Sebastián Montero de Espinosa, nuevo propietario de la casa de Juan Bravo de Jerez ${ }^{24}$ «con sus plazas y sitios a ella anejos y pertenecientes», puso interdicto ante el licenciado don Pedro del Alamo, teniente de alcalde mayor ${ }^{25}$, exigiendo «que se deshagan los cimientos y se allanara la plaza a su antiguo estado" por ser el sitio particular, por haberse labrado en él sin el consentimiento de sus dueños ${ }^{26}$ y por la

19 Este señor, caballero de la orden de Calatrava, vecino de Bilbao y residente en Madrid, era entonces el propietario de de la antigua morada de Juan Bravo de Jerez, «con todas las plazas y sitios anejos» (Archivo del convento de Ntra. Sra. de la Merced, carpeta de varios).

$20 A D P B$, sig. $17,2 .^{\circ}-28$.

$21 A D P B$, sig. 17, 2.-28.

22 Juan Bravo de Jerez había comprado dos casas viejas que pertenecieron a Isabel Gutiérrez y que estaban frente a la fachada principal de su finca. Por ser estrecha la calle del Pozo - hoy de Menacho-, mando derribarlas y allanar el terreno para hacer del solar una plazuela que diera luz y vista a su vivienda ( $A D P B$, sig. $\left.17,2 .^{\circ}-28\right)$.

23 Fueron los regidores don Gonzalo de Hoces Mogollon y don Francisco de Moscoso Maldonado ( $A M B$, l.a. n. ${ }^{\circledR}$, f. 272 vto.)

24 La compró a don Pedro de Segovia Ibáñez por 3.500 ducados. La transacción se hizo en Madrid el 19 de julio de 1630, y el 8 de septiembre, en presencia del corregidor don Luis Andrés de Godoy Ponce de León, tomó posesión legal del inmueble (Archivo del convento de Ntra. Sra. de la Merced, carpeta de varios). Hasta 1632 la tuvo arrendada, y vivió en ella, el mencionado corregidor ( $A H P B$, prt. 283, f. 447), al que el 20 de febrero de dicho año contradijo su nombramiento el Consistorio por no residir ya en la ciudad ( $A H P B$, prt. 296, f.62). A partir de esa fecha, y hasta su muerte, la habitó Sebastián Montero de Espinosa ( $A H P B$, prt. 276, f. 136). Vid. también nota $\mathbf{n}^{9} 8$.

25 Ejercía el cargo por ausencia del justicia titular don Luis de Escobedo (AMB, l.a. n. 94 f. 197).

$26 A D P B$, sig. 17, 2.9-28. Es muy probable que Sebastián Montero, regidor de la ciudad desde 1612 y capitán de las milicias concejiles desde 1629, hubiera aprobado en su día la construcción del teatro, y eso a pesar de su probada animadversión hacia el marqués de Villamagna ( $A H P B$. prt. 264 , s.f., 12 de mayo, 1628). 
gran minusvaloración que sufriría la casa $^{27}$ con el edificio del corral enfrente «por ser la calle muy angosta y perder la claridad (...) y la vista del frontispicio de ella». El juez traslada la demanda al consistorio, el cual resuelve defender los intereses de la ciudad en todos los cauces y por todos los procedimientos ${ }^{28}$. El 5 de septiembre de 1633 el procurador Diego Martín Guisado contradice de calumnia las alegaciones de Sebastián Montero ${ }^{29}$ por no poderse «demoler ni derribar lo edificado (...) por ser el sitio de esta ciudad». La sentencia ignoró ese fundamento, declaró de propiedad particular el solar y ordenó al municipio derribar lo construido. El ayuntamiento, a pesar de que consintio el fallo el 21 de octubre de 1633, demoró su ejecución por haberlo apelado y contradicho en segunda instancia tres capitulares que le negaron su acatamiento ${ }^{30}$. El 1 de mayo de 1634 Sebastián Montero reclama ${ }^{31}$, y consigue, la observancia del auto "porque está la plazuela de forma que no se puede andar por ella, y tiene mucha tierra, estiércol, basura y otras muchas incomodidades». El día 15 del mismo mes ya se habían iniciado los trabajos de demolición y el 6 de noviembre ya estaban concluidos ${ }^{32}$. La piedra de los cimientos se regaló, «sin otro interés que sacarla y allanar el sitio», a las monjas jerónimas del cercano monasterio de San Onofre para que la utilizaran en la reforma que hacían en el claustro del convento ${ }^{33}$.

El repentino avenimiento que mostró la mayoría de los regidores a peticiones que antes habían rechazado, y la dejación que hicieron en la defensa de los legítimos y legales intereses de la ciudad, declaran su presunta connivencia con Sebastián Montero de Espinosa. Esta confabulación fue denunciada por algunos capitulares no comprometidos: El 6 de noviembre de 1634 don Francisco de Chaves y don Miguel de Vargas, que por el buen predicamento

27 ADPB, sig. 17, 2.9-20. La depreciación que alegaba era de más de 3.000 ducados, quebranto desorbitado dado el valor de mercado, unos 4.000 ducados, que por entonces tenía la vivienda. La alegación que transcribimos de Sebastián Montero parece copia de la afirmación de Cetio Faventino, editado en 1540 , de que «la belleza de una construcción urbana radicará en su luminosidad, máxime cuando en las inmediaciones no haya paredes altas que la estorben».

${ }^{28}$ Los encargados de tramitar este negocio fueron don Gonzalo de Hoces Mogollón y don García Laso de la Vega.

29 ADPB, sig. 17, 2.-28.

30 Se opusieron tres capitulares: don Gonzalo de Hoces Mogollón, don García Laso de la Vega y don Francisco de Chaves (AMB, l.a. n. ${ }^{9} 3$, f. 421).

31 AMB, l.a. n. ${ }^{2} 4$, f. 36.

32 El concejo encomendó al regidor Domingo García el que gestionara las obras para deshacer los cimientos y allanar la plazuela ( $A M B$, l.a. n. ${ }^{9} 4$, f. 39 vto.).

33 Se ocuparon de ese trabajo los oficiales del maestro de albañil Simón Hernández, que hacía la ampliación del claustro ( $A M B$, , la. n. ${ }^{9} 4$, fs. 39 vto. y 73 vto.) 
que ambos gozaban entre los vecinos, probada rectitud y consolidada hacienda poco temían de las intrigas y malicias de Sebastián Montero, piden en cabildo $^{34}$ que «no se llegue a cosa alguna de lo que está en el dicho corral, ni se prosiga en demoler la dicha obra hasta tanto que la Real Chancillería lo mande. Y lo piden por testimonio». Y mucho más rigurosas, casi ofensivas, fueron las imputaciones que mantuvo el regidor don Pedro de León de $\operatorname{Vargas}^{35}$ en el ayuntamiento del 25 de octubre de 1635. Protestó de que los comisarios que la ciudad nombró para su defensa actuaron «con notoria omisión y coacción»; de que los concejales que acataron la sentencia del licenciado Pedro del Alamo, contravinieron «las leyes del reino que hablan en la defensa que se debe hacer en los pleitos que se siguen en las ciudades contra sus cabildos», y de que al no haber hecho uso de oficio del amparo que ofrecían otras disposiciones de derecho público y del fuero de Badajoz, «ha resultado que a esta ciudad se le ha seguido notorio agravio (...), y pérdida de mucha cantidad de maravedises por haberla despojado del sitio que era suyo propio, y demolido el edificio que en él tenía hecho, de que se le seguía mucha autoridad y útil para sus propios». Y tras estas alegaciones, "y para que la ciudad consiga la justicia que tiene (...) en razón de lo referido», solicita el nombramiento de comisarios que «pidan restitución contra la dicha sentencia y ejecución de ella (...), y sigan el dicho pleito en esta instancia y ante el tribunal superior» hasta que «dicha obra se ponga en el estado que estaba antes que se demoliese». Aunque el ayuntamiento asumió el compromiso de entablar «todos los autos y diligencias judiciales y extrajudiciales sin ninguna limitación», sólo consiguió rescatar para el dominio público la titularidad del solar, pero fracasó en la demanda de que se rehiciera la cimentación del teatro. El cabildo del 7 de mayo de 1640, muerto ya Sebastián Montero ${ }^{36}$, «porque el gasto que se hizo en sacar los cimientos no fue mucho, y la mayor parte se volverá a restaurar con volver los sitios de los corrales que había comprado de particulares a sus dueños, que fue lo más considerable», abandona definitivamente la ubicación del corral en ese sitio para levantarlo en la calle del Dómine Galindo ${ }^{37}$ donde se podría labrar «con menos costa que si se prosiguiese, pudiéndolo hacer, el comenzado», y además «con mucha mayor grandeza». El terreno sin embargo se mantuvo como plazuela para no entorpecer el acceso a dos casas principales que entre tanto se habían levantado en ella $^{38}$.

34 AMB l.a. n. 9 , f. 73 vto.

35 AMB, l.a. n. 9 , f. 197.

36 Fallecio el 14 de septiembre de 1639.

37 AHPB, prt. 292, f. 88.

38 Estaban al otro extremo de la plaza, enfrente de la de Sebastián Montero. Una era la de don Baltasar Bravo de Laguna; en ella vivió durante la guerra contra Portugal el duque de San Ger- 
Desconocemos la traza de ese teatro, que sin duda la hubo, así como cualquiera otra documentación que nos informe sobre su autoría, observaciones arquitectónicas, acuerdos económicos, libramientos, etc., y creemos que nunca se conocerán: En la noche del 18 de noviembre de 1679 se declaró un pavoroso incendio en las casas consistoriales, y las llamas consumieron los fondos que venía atesorando su archivo desde finales del siglo $\mathrm{XIII}^{39}$.

Desechada la construcción del patio de comedias en la céntrica calle del Pozo, los regidores, «deseosos del bien de su ciudad», acuerdan el 7 de mayo de 1640 adquirir una casa deshabitada que don Miguel de Mendoza y su hermana doña Isabel de Chaves ${ }^{40}$ poseían en la calle del Dómine Galindo ${ }^{41}$, en cuyo amplio solar y con poco costo ${ }^{42}, 2.000$ ducados, se podría labrar «obra tan pública y necesaria». Dos meses después, el 18 de julio, se formaliza la compra ante el escribano Manuel de León, abonando el Ayuntamiento por el inmueble 5.500 reales en pagos aplazados ${ }^{43}$. A pesar del probado interés que mostró el concejo por edificar pronto el teatro por el «mucho útil y aprovechamiento»

mán, capitán general del Real Ejército de Extremadura; en 1670 la compró por 200 ducados don Manuel de Avila (AHPB, prt. 364, f. 231). Y la otra, lindando con ella, era la de don Alonso de Figueroa. Las dos ya aparecen construidas en 1640 (AHPB, prt. 210. f. 221). Hoy el sitio de ambas lo ocupa el palacio del Gobiemo Militar.

39 Muchos de sus viejos documentos los utilizó don Juan Solano de Figueroa, cuando, a mediados del siglo XVII, redactaba su monumental obra Historia Eclesiástica del Obispado de Badajoz. Otro fuego, esta vez el 16 de septiembre de 1880 , destruyo lo poco que entonces pudiera haberse salvado.

40 Este punto debería haberse tratado en el cabildo del 15 de marzo de 1640, pero ni ese día, ni tampoco el 22 del mismo mes, se celebraron juntas ordinarias por la ausencia intencionada del corregidor don Mendo de Contreras. Estas anomalías dieron ocasion a que el regidor don Francisco de Moscoso impugnara el acuerdo por falto de forma. Las casas habian sido inspeccionadas previamente por dicho corregidor acompañado de don Fernando Becerra, alférez mayor de la ciudad, de don Gonzalo de Hoces Mogollón, alcalde mayor del Consistorio, y de los regidores don Juan de Vargas y don Francisco de Chaves (AMB, l.a. n. ${ }^{2}$, fs. 82 vto. y 107 vto.; $A H P B$, prt. 292, f. 89).

41 La finca, herencia de su padre, don Antonio de Mendoza y Chaves, era el segundo edificio de la calle, a la mano derecha, entrando en ella desde el campo de San Juan. El primero, que hacía esquina con la calle de Ana de Thovar - hoy López Prudencio-, pertenecía a don Francisco de Moscoso Maldonado ( $A M B$, Libro de acuerdos del año 1640, f. 31).

42 Su superficie permitía que la planta del teatro fuera de «mucha mayor grandeza» que la proyectada en la plazuela de Juan Bravo de Jerez. Para abaratar la obra se pretendfa aprovechar como cimentación y muros maestros las solidas paredes del inmueble (AMB, l.a. n.9 6, f. 106 y $A H P B$, prt. 292, f. 88). El gasto se cargaría sobre los ingresos de arbitrios, aplicación ya autorizada por real provisión de 20 de diciembre de 1629 (AMB, l.a. n. ${ }^{9} 4$, f. 83 y l.a. n. ${ }^{9} 6$, f. 85 vto.).

${ }^{43} A H P B$, prt. 292 , f. 84 y prt. 292, f. 85 vto. 
que le traería su arriendo ${ }^{44}$, la guerra contra Portugal (1640-1665) demoró su ejecución hasta 1669.

A mediados de dicho año, en el ayuntamiento del 23 de mayo de 1669, se leyó un escrito que le habían elevado los hospitales de la Vera Cruz, Concepción y Piedad solicitándole la donación de esa casa para levantar a costa de sus fondos el anhelado coliseo ${ }^{45}$. Como contrapartida ofrecían al consistorio la titularidad perpetua de un palco «en lugar preeminente (...) en donde V.S., si quisiere, pueda asistir a ver representar las comedias que se hubieren de hacer». Los capitulares consienten en la enajenación «por haberse comprado (...) para dicho efecto, y ser tan del servicio de Dios nuestro Señor el que por este medio tengan alguna limosna dichos hospitales, como la tienen en todas las ciudades del reino». A estos motivos pueden añadirse, aunque no se indican en la minuta, otras consideraciones menos altruistas: Que, tras largos años de abandono, se había minorado tanto el valor del edificio - sólo quedaban en pie las paredes maestras-, que la transferencia gratuita no supondría grave quebranto para la hacienda municipal ${ }^{46}$; que el precio del balcón que se le entregaría a cambio superaba con creces la tasación actualizada de la finca, y que por entonces no disponía la municipalidad de 5.400 ducados para invertirlos en esa fábrica ${ }^{47}$.

La mentada petición, al igual que el fallo favorable, no fueron más que meros trámites administrativos que legitimaban una decisión previamente acordada. El hecho de que unos días antes, el 11 de mayo, los hospitales hubieran

44 Existra una oferta en firme de 200 ducados de renta. Hubo además un promotor privado, posiblemente relacionado con don Francisco de Moscoso, que se comprometia a edificarlo a su costa siempre que el ayuntamiento le autorizara su explotación, propuesta que no fue aceptada «porque no es decente a una ciudad tan ilustre y antigua como esta, que un edificio tan público tenga otro dueño que esta ciudad» (AMB, l.a. n. ${ }^{\circ}$ 6, f. 107 vto.).

45 Lo presento el procurador Lorenzo Pavón en nombre de los hospitales de la Vera Cruz, Concepción y Antigua Piedad (AHPB, prt. 329, f. 646).

46 Ya en 1647, cuando el municipio alquilo la casa por seis años a don Alonso de Mesía para establecer en ella su morada, tuvo que repararla el arrendatario por hallarse «sin puertas ni techo, por haberlo hurtado todow ( $A M B$, l.a. n. 8, fs. 22 y 24 vto.). En 1665 don Francisco Domingo, alferez mayor de la ciudad y arquitecto militar, y el regidor don Miguel Montero del Moral, informaron al ayuntamiento «de los reparos que necesita por haberse cardo parte de ella, y que necesita de taparse dos portales por ahora hasta que haya material de ladrillos y tejas para que se pueda cubrir» (AMB, l.a. n. ${ }^{2} 11$, f. 30).

47 La larga guerra de la independencia de Portugal aniquilo la rica producción agropecuaria del término municipal de Badajoz, asolo diversos asentamientos humanos y puso en fuga a gran parte de su población civil. Estos agentes de degradación económica empobrecieron el municipio y privaron al ayuntamiento de gran parte de sus ingresos por arbitrios y arrendamiento de propios. 
aceptado el proyecto de obra del alarife portugués Juan Bautista Machado48; el que ya tuvieran prevenida su financiación ${ }^{49}$ con el plácet del obispo don Francisco de Rois y Mendoza; el que se firmara el contrato en el domicilio del corregidor de la ciudad; el que fuera testigo del otorgamiento el alférez mayor don Francisco Domingo, y el que todas estas diligencias fueran sobradamente conocidas por los ediles, constancia que se apunta en el escrito rogatorio, confirman el puro formalismo de la gestión.

El 27 de mayo de 1669 dicho alférez mayor y el regidor Juan Moreno Juárez legalizaron la transferencia de dominio ante el escribano José Serrano Barradas $^{50}$.

La edificación del teatro debió de iniciarse a principios de junio de $1669^{51}$ y concluirse hacia finales del año siguiente. La cláusula decimosexta del contrato de obra exigía de Juan Bautista Machado entregar la fábrica «acabada (...) con toda perfección a fin de marzo del año que viene de seiscientos

48 Se elevó a escritura pública el 11 de mayo de 1699 ante el escribano Nicolás Vázquez y en presencia del corregidor don José de Tapia. Firmaron como compromisarios el arquitecto Juan Bautista Machado y los regidores de los hospitales don Iñigo de Argüello Carvajal, don Nuno de Chaves, don Juan de la Rocha, don Juan de Alvarado, don Rodrigo de Brito, don Juan de Vargas y don Francisco de Chaves Sotomayor. El contrato consta de una exposición de motivos, de dieciocho apartados (dos de garantías, doce de precisiones técnicas y cuatro de estipulaciones económicas) y de una conclusión de estilo ( $A H P B$, prt. 329, f. 359). Se complementaba con un diseño de planta y alzado (vid. láminas 3 y 4). Este interesante documento, conocido de antiguo por el autor de este trabajo y otros investigadores, fue publicado por don Carmelo Solís Rodríguez en excelente transcripción y con oportunos y eruditos comentarios ( $\mathrm{EL}$ corral de comedias de Badajoz» en Memorias de la Real Academia de Extremadura de la Letras y las Artes, v. 1, Trujillo, 1983, pp. 379 y ss.).

49 El 23 de mayo de 1669 ya tenfan concedida los hospitales la autorización del provisor del obispado para conseguir los 5.400 ducados del costo por la enajenación de rentas y propiedades, o por la imposición de censos sobre sus bienes ( $A M B$, , la. n. ${ }^{\circ} 12$, f. 5). El 27 de septiembre de 1669 el hospital de la Concepción solicita del vicariato el permiso necesario para tomar a censo de doña María de Silva, monja en el convento de Santa Lucía, los 1.000 ducados que aún necesitaba para completar su tercio obligado del importe del patio de comedias ( $A H P B$, prt. 329, s.f.), petición que le fue concedida el 9 de octubre ( $A H P B$, prt. 329, s.f.) y formalizada en escritura pública dos días más tarde (AHPB, prt. 329, f. 819). El 14 de enero de 1670 fue el hospital de la Antigua Piedad el que solicita del corregidor de la ciudad que se le permitiera la inscripción notarial de un censo cuya cantidad resulta ilegible en el escrito ( $A H P B$, prt. 360, f. 29).

50 AHPB, prt. 359 , s.f.

51 El 28 de mayo no habían comenzado las obras, pues en la carta de pago de 5.500 reales que extendió ese día Juan Bautista Machado en favor del hospital de la Concepción, se anotan que eran «para en cuenta de la obra que dicho otorgante ha de hacer del corral de comedias de esta ciudad» (AHPB, prt. 356, f. 135). Sin embargo, en el recibo de 250 ducados que firmó el 21 de junio para el hospital de la Vera Cruz ya indicaba que lo eran «por el patio de comedias que fabrica en esta ciudad» (AHPB, prt. 329, f. 515). 
y setenta»; sin embargo, cuatro meses más tarde, el 20 de julio, aún no lo había cumplido ${ }^{52}$, aunque no debió de retrasarlo mucho por las penalizaciones que gravaban la demora. En el verano de 1671 ya estaba dispuesto el local para su uso ${ }^{53}$, y sin duda el acondicionarlo requirió bastante tiempo.

La cantidad de 5.400 ducados $-\mathbf{5 9 . 4 0 0}$ reales - en que se presupuestó a la baja la edificación del teatro, tuvo que incrementarse de forma considerable, probablemente en casi el doble, a lo largo de su ejecución ${ }^{54}$. En una liquidación quinquenal, del 3 de mayo de 1668 al 4 de mayo de 1673, inserta en el libro de caja del hospital de la Vera $\mathrm{Cruz}^{55}$, Diego Fernández, su mayordomo, registra «un cuento y ochenta y cuatro mil novecientos y setenta y cuatro maravedís - 31.911 reales - que pagó en diferentes días y partidas a Juan Bautista Machado, maestro de albañil, (...) para la obra que se hizo en la casa de comedias». Si ese apunte refleja la tercera parte del costo final, cosa probable pues ésa era la fracción obligada para cada uno de los tres hospitales, el finiquito del alarife portugués pudo ascender a 95.733 reales. Aunque desconocemos la cuantía exacta - no hemos hallado esa certificación, documento que sin duda existio ${ }^{56}$ por haberse saldado su importe con múltiples entregas a cuenta-, dicha cifra nos resulta admisible dada la grandeza del proyecto, la exigencia ${ }^{57}$ de «que todos los materiales han de ser de buena ca-

$52 A H P B$, prt. 330, f. 318.

$53 A H P B$, prt. 331, f. 363.

54 Este encarecimiento no podemos considerarlo como un fenómeno aislado y singular en este tipo de construcciones: Se estima que el patio de comedias de Jaén, inaugurado en 1674, importó unos doce mil ducados (Luis Coronas TEjada, «Casas de comedias en el reino de Jaén», en Teatros y vida teatral en el Siglo de Oro, Londres, 1991, p. 147). La nueva casa de comedias de Málaga, iniciada en 1676, se ajustó en 20.000 ducados, pero su costo final superó los 34.000 (Tres siglos de teatro malagueño, op. cit., p. 68). Y mucho antes, en 1601, cuando Juan de Ochoa se compromete a levantar el teatro de Córdoba, presupuestó la obra entre diez y catorce mil ducados (Angel M. GARCIA Gómez, La casa de comedias de Córdoba, Londres, 1990, p. 15).

$55 A D P B, \lg .19$, libro de cuentas, f. 21.

$56 \mathrm{El}$ pago de la fábrica por tramos ultimados estaba contemplado en el punto 17 del contrato, aunque no creemos que se cumpliera en sus propios términos. Los recibos que hemos visto nunca son liquidaciones de obra hecha, sino más bien justificantes de provisiones de fondos. Confirman estos anticipos el contenido de la cita transcrita, el finiquito de 5.000 reales por cuatro partidas otorgado por Juan Bautista Machado en favor del hospital de la Vera Cruz (AHPB, prt. 331, f. 392), y las ocho libranzas cuyos totales detallamos a continuación: sobre el hospital de la Antigua Piedad, 14.200 reales en tres cartas de pago (AHPB, prt. 359, s.f. [26 de diciembre, 1669] y prt. 360 , fs. 31 y 42); sobre el hospital de la Concepción, 5.500 reales en una carta de pago ( $A H P B$, prt. 360, f. 29), y sobre el hospital de la Vera Cruz, 20.000 reales en cuatro cartas de pago ( $A H P B$, prt. 329, fs. 515 y 672, y prt. 330, fs. 245 y 318). Don Fernando CASTón DURÁN, en Rincones de la historia extremeña (Badajoz, 1945, p. 160), sostiene que el importe de la obra fue de 6.000 ducados -66.000 reales - , pero no precisa la fuente documental del dato.

57 Punto 11 del contrato de obra. 
lidad, así mezclas de cal y arena, ladrillos, teja, madera y manufactura», y sobre todo por el desmesurado encarecimiento que experimentó la construcción en Badajoz tras la guerra contra Portugal. Entre los testimonios de tal inflación, y pudiéramos relacionar muchos, aportamos sólo uno por referirse a esta obra: Manuel Rodríguez percibió 342 reales por el porte de diez acarreos de remate, un mes de servicio de su carreta y cuatro jornadas de trabajo personal $^{58}$. Fueron sin duda estipendios tan elevados los que provocaron el mencionado desajuste al alza.

Ignoramos la inversión que hicieron los hospitales en utillaje y en los necesarios retoques - telones, cordería, poleas, maquinaria, bancos, anclajes, etcétera-, pero la suponemos importante: sólo por la madera para el tablado, y es nuestra única referencia, se pagaron 2.496 reales $^{59}$.

Hemos dicho que demediado 1671 ya se podía utilizar el corral, y nos apoyamos en estos datos: El 14 de julio la compañía de Jerónimo de Heredia ${ }^{60}$ se comprometió a hacer «cuarenta representaciones en el patio de comedias que en esta ciudad hay, desde el mes de agosto en adelante», y unos días después, el 31 de julio, el cabildo catedralicio comisiona a los canónigos don Martín Calderón y don Francisco de Zaldívar para que reconocieran los palcos y arrendaran uno conveniente ${ }^{61}$. Pero al parecer su construcción no fue tan robusta y cuidada como exigía el proyecto. En 1673 falló el muro de la fachada provocando el derrumbe de parte del vestíbulo ${ }^{62}$. Ese año los hospitales destinaron 6.000 reales para reconstruirlo, y en 1674 , «dada la suma necesidad por falta de sus rentas», solicitaron del Ayuntamiento una subvención de otros 2.000 para

58 AHPB, prt. 1151, f. 306 vto. El casi coetáneo Diccionario de Autoridades (1726-1739) define remate como «Lo que se sobrepone en las fábricas de arquitectura u otras cosas, para terminar o encrespar las extremidades de ellas, sirviendo de adorno y hermosura».

59 Para construir el escenario se utilizaron 156 tablones, cuyo precio era de a 16 reales la unidad. El importe total de la madera, 2.496 reales, lo pagó el hospital de la Vera Cruz al proveedor Juan Bautista Zavala ( $A D P B$, lg. 19, libro de cuentas, f. 21 ).

$60 A H P B$, prt. 331 , f. 363.

61 El abono anual fue de 150 reales (ACB, l.a. n. ${ }^{2} 14$, f. 150, l.a. n. ${ }^{2} 19$, s.f., 6 y 9 de julio, 1687).

62 Es muy probable, aunque no tenemos verificación documental de ello, que esa pared fuera una de las tapias aprovechadas de la morada de don Miguel de Mendoza que, por su envejecimiento, le faltó solidez para soportar la sobrecarga de las bóvedas. La reparación tuvieron que hacerla a su costa los hospitales, y no el alarife, por haber expirado el tiempo de garantía acordado en el contrato: ky si dentro del año y día que se asegura la dicha obra, contado desde el día que se acabare, algún riesgo o daño tuviere la dicha obra, o se reconociere por cualquier caso fortuito acontecido $o$ por acontecer del cielo a la tierra (...), ha de ser por cuenta del dicho Juan Bautista Machado, y volverlo en lo que así se reconociere a fabricar con toda perfección, sin que por ello haya de llevar más interés que el que está ajustado». 
«que quedase perfecta dicha obra». El 4 de diciembre accede el consistorio «por esta vez (...) visto que es una obra pública y de tanta conveniencia para la limosna que se saca para dichos hospitales», y ordena el libramiento ${ }^{63}$. La reedificación concluyó en 1675 , y desde esa fecha no hay constancia de nuevos hundimientos.

El examen minucioso de los detallados planos -planta y alzado- «que se habían de observar y guardar», y que «en un pliego de papel» se adjuntaron al contrato de obra ${ }^{64}$, y también la atenta lectura de los pormenores técnicos que se recogen en el proyecto, nos permiten describir con bastante fidelidad la configuración arquitectónica de la «casa del teatro».

El edificio, dispuesto sobre una superficie de 652 metros cuadrados ${ }^{65}$, funde en un conjunto armónico dos espacios claramente diferenciados: uno anterior, rectangular y estrecho con 26 metros de fachada a la calle, y otro posterior, amplio y desembarazado, en medianería con el primero ${ }^{66}$. Esta área, destinada a las representaciones, abandona en su diseño el trazado rectilíneo del típico corral castellano y sigue el corte ovalado de los teatros renacentistas de Vicenza y Ferrara, opción más acertada por sus mejores condiciones de visibilidad y acústica. Sin embargo, el patio de Badajoz no puede considerarse como un calco fiel de esos modelos o como una adaptación de sus imitaciones españolas $^{67}$ : su doble simetría axial ${ }^{68}$, que tanto le separa de la típica forma de herradura del patrón italiano, sus dos pisos de galerías arqueadas, sus pilares toscanos y su cornisamiento corrido, le asemejan mucho a los hermosos atrios de los suntuosos palacios barrocos ${ }^{69}$.

63 El regidor don Manuel de Herrera se opuso a la concesión e impugnó el acuerdo. El 8 de julio de 1675 el Consejo de Castilla lo declara nulo y obliga a los capitulares a restituir ese dinero a la ciudad ( $A M B$, l.a. n. ${ }^{9}$ 14, f. 189 y l.a. n. ${ }^{2} 15$, f. 118).

64 Se reproducen como apéndice a este trabajo (láminas 3 y 4 ).

65 La del corral de Zamora, ciudad entonces con una población muy aproximada a la de Badajoz, era de 425 metros cuadrados (C. M. VENTURA CRESPO, «El corral de comedias de Zamora», op. cit. Teatros y vida teatral, p. 87), y la del patio de Córdoba, localidad con 40.000 habitantes, era de 808 metros cuadrados (Angel M. GARcía GÓMEZ, op. cit., lámina cero).

66 Las superficies construidas fueron de 142 metros cuadrados para el cuerpo anterior y de 510 metros cuadrados para el cuerpo posterior.

67 El teatro de la Olivera de Valencia, el del Buen Retiro de Madrid, el de Murcia, el nuevo de Valladolid o el de Calahorra. Para una sucinta revisión histórica de la preocupación por la visibilidad y acústica en arquitectos e ingenieros, vid. Antonio TORDERA, «El circuito de apariencias y afectos en el actor barroco», en Actor y técnica de representación del Teatro Clásico Español, Londres, 1989, pp. 130-132 y 135.

68 El diseño de la planta resulta de insertar un rectángulo en un decágono seccionado por la diagonal del eje menor del 6valo que lo inscribe (láminas 1 y 2 ).

69 Por este teatro, y por otras obras sabidas de Juan Bautista Machado, pensamos que el alarife portugués conocía los tratados de arquitectura de Vitruvio, Alberti, Serlio, Vignola y Palladio. 
Sobre sólidos cimientos de piedra y cal de $84 \mathrm{cms}$. de ancho, sacados desde el firme y levantados en zócalo hasta «media vara ${ }^{70}$ más alta que la superficie», se alzaban los muros maestros, hechos de tapial reforzado con machones y verdugos de ladrillo y enfoscados con hormigón hidráulico ${ }^{71}$. En el paramento externo las rafas que soportaban el empuje de las bóvedas de los corredores estaban afirmadas con contrafuertes «hasta la altura necesaria». El peralto de la obra de carga, desde el ápice al nivel del terreno, era de 7,30 metros.

El cuerpo de entrada se alzaba con su doble planta en esa franja rectangular y estrecha que lindaba con la vía pública. La crujía del piso bajo ${ }^{72}$ estaba fraccionada en tres piezas de dimensiones casi idénticas ${ }^{73}$ que hacían de vestíbulos; vanos abiertos en los muros transversales franqueaban el paso por el interior de esa nave ${ }^{74}$. El recibidor central, cubierto por tres bóvedas de arista, se comunicaba con el exterior por una puerta bocelada de metro y medio de anchura, y con el patio a través de los tres arcos sobre pilastras que soportaban el piso superior en sus ocho metros y medio de frente ${ }^{75}$; los dos laterales, techados con bóvedas de medio cañón, tenían sendos portillos a la calle ${ }^{76}$ y de ellos arrancaban las escaleras de subida a la galería alta ${ }^{77}$. Desde el zaguán izquierdo se podía acceder al patio por dos aberturas contiguas de ochenta centímetros, huecos que en el testero del zaguán derecho se habían tabicado, posiblemente por ser aledaños al tablado y a los vestuarios ${ }^{78}$. El piso superior, de idéntica medida y distribución, presentaba tres ventanas a la calle en simetría con las puertas de entrada, y se abría al patio por cinco balconadas con apo$\operatorname{sentos}^{79}$. Adornos de remate coronaban el paramento del frontis ${ }^{80}$.

70 Son 42 centímetros.

71 Punto cuarto del contrato.

72 Su medidas interiores eran de 25 por 4 metros.

73 Treinta, treinta y cuatro y treinta metros cuadrados respectivamente.

74 La anchura de cada una era de ochenta centímetros.

75 Esta configuración haría imposible pagar la entrada en dos abonos distintos en puertas diferentes -el tanto de la empresa y el tanto de la compañía-, fórmula muy común en aquellos tiempos.

76 Sus anchuras eran de un metro.

77 «Que para subir a los corredores y sitio de la ciudad y cazuela, se le ha de hacer sus escaleras de ladrillo y cal proporcionadas de largo, y alto el que necesitare» (punto octavo del contrato de obra). Eran dos: una desde cada zaguán y se indicaban en el plano con líneas punteadas. Es muy posible que para salvar los 3,8 metros de desnivel entre los pisos de las dos plantas, la longitud de cada una fuera de 5,5 metros con 19 peldaños de 29 centímetros de huella y 20 de contrahuella.

78 Cabe suponer, si eso fuera cierto, que el tabique tendría una puerta con cerradura para entrada de los actores.

79 Es muy probable que en este piso, y para facilitar el tránsito del público a palcos y escalera, no estuvieran clausurados los accesos a la galería desde la estancia derecha.

80 Vid. nota 28 . 
La estructura del patio, de sencilla belleza y digna prestancia, la formaban pilastras toscanas superpuestas de ajustadas proporciones ${ }^{81}$, asentadas sobre basas del mismo orden y con las molduras de sus capiteles -golas, junquillos y filetes - prolongadas en toda la cornisa. Sus caras laterales, por ser soportes compuestos, se ensanchaban en dos resaltes donde, a modo de cortas jambas injeridas ${ }^{82}$ y sobre impostas, se apoyaban los arcos de medio punto ${ }^{83}$ que sostenían el entablamento con enjutas guarnecidas con fajas al borde. En su frente posterior otros salientes mantenían los arcos formeros y las aristas de las bóvedas esquifadas que, descansando sus otros extremos sobre ménsulas labrabas en los muros, techaban con fábrica de ladrillo el peristilo del atrio ${ }^{84}$.

En el pórtico bajo un corredor arrancaba desde los extremos de la zona de vestíbulos y abrazaba la platea por tres de sus costados. Las alas izquierda y central se utilizaban como vía de tránsito hacia los asientos. El cuerpo derecho lo suponemos dedicado al servicio exclusivo de la escena y de los actores.

La galería superior estaba ocupada por los aposentos. El municipal, muy espacioso, extendía su balcón de ristreles torneados bajo los tres arcos centrales del fondo izquierdo ${ }^{85}$, y a sus flancos, en las alas laterales, se hallaban los palcos de arriendo. Eran éstos diez pequeños compartimentos ${ }^{86}$ de 1,75 metros de fondo y de 2,50 62,75 metros de frente ${ }^{87}$, recercados con una pared de tabiquería de 1,90 metros de altura, que se abrían hacia la platea y el tablado por los claros entre pilastras. Unas angostas puertecillas les daban entrada desde el estrecho pasillo que contorneaba el perímetro del patio ${ }^{88}$, y unas barandillas «de palos redondos o quebrados de altura suficiente» les servían de antepechos ${ }^{89}$. Es muy probable que los tres tramos fronteros al lugar del

81 Las inferiores, con catorce módulos, median 3,90 metros, y las superiores, con trece modulos, 3,62 metros.

82 De 1,80 metros las del piso bajo y de 1,50 las del alto.

83 Tenían de radio 1,25 metros.

84 Las disposiciones contenidas en los apartados 3, 5, 6, 10 y 17 del contrato de obra sugieren esta clase de techado para ambas galerías. Sólo se exceptúa la cubierta del aposento del concejo por ser ésta de alfajía enladrillada.

85 Se marcó en el plano con una acotación rectangular hecha a mano alzada. En los teatros de Córdoba y Jaén también disponía el Ayuntamiento de un balcón de tres arcos en el corredor alto (op. cit. Teatros y vida teatral, p. 102).

$86 \mathrm{Si}$ los tres intercolumnios enfrentados a los del balcón del ayuntamiento no se utilizaran para albergar los juegos de escena, empleo que consideramos casi seguro, serían entonces trece el número de palcos disponibles.

87 Estas medidas son algo superiores a los ocho pies de frente por seis de fondo $-2,23$ por 1,67 metros-que eran las habituales de los palcos en los teatros españoles.

88 Medía $84 \mathrm{cms}$. de ancho.

89 Puntos 12 y 13 del contrato de obra. 
Concejo, no estuvieran habilitados para acoger espectadores: pensamos más bien que por su situación en el foro se utilizaron como fachada del teatro y también para fijar en ellos algunos juegos de tramoya.

La zona «de todo andar por debajo de las bóvedas y por encima de ellas» estaba solada con ladrillos y «las paredes, pilares, arcos y bóvedas encaladas con todo lucimiento» ${ }^{90}$. Cabe suponer, aunque no se apunte en el pliego de condiciones - tal vez por ser normal en los corrales-, que el suelo del patio estuviera empedrado.

La existencia de la cazuela, reservado femenino característico de los teatros castellanos, queda manifiesta en la cláusula séptima del contrato de obra: «que sobre el espacio que ocupa el cuarto que se ha de fabricar para la ciudad, se ha de hacer sobre ello un doblado alfajiado de ladrillo por tabla, con otro suelo por arriba de ladrillo que sirva de cazuela para las mujeres». La superposición que se indica entre ambas localidades no nos sugiere ningún comentario especial: era una fórmula frecuente y antigua en los corrales ${ }^{91}$; pero sí lo motiva la encamadura del piso de ese desván, medida que no se menciona en el convenio ni puede extraerse del alzado. Cabría la posibilidad de que la alfajía se hubiera construido sobre las paredes que cerraban el palco municipal, supuesto muy improbable por la poca elevación, 1,90 metros, que se hubiera dado al techo de lugar tan preeminente, $y$, lo que es más conclusivo, por las pésimas condiciones de visibilidad que habría tenido la cazuela de aprovecharse como ventanas un sector de las cintras de los tres arcos ${ }^{92}$. Es más acertado pensar que el solado se hiciera en la parte inferior del entablamento y que el resto de la comisa sirviera de pretil. Desde ese lugar la mirada de las espectadoras apenas tendría estorbos, s6́lo el entramado del tejado podría dificultarles en algo el panorama de la escena ${ }^{93}$.

Una conjetura muy verosímil es que los vestuarios estuvieran en la galería inferior, detrás del foro; que en la superior, sobre el tablado, se hallara, y ya lo hemos comentado, el balcón de las apariciones «en alto» ${ }^{94}$, y que, culminando

90 Puntos quinto y sexto del contrato.

91 Así estaba en los afamados corrales madrileños de la Cruz y del Príncipe. J. E. VAREY en Op. cit., p. 209, escribe sobre ellos: «Frente al tablado, y el piso primero, se encontraba la parte del teatro reservada para las mujeres, una galería o aposento grande que se denominaba la cazuela; encima de la cazuela estaba el aposento del Ayuntamiento».

92 Aunque la longitud de la cuerda de arranque puede considerarse suficiente $-2,50$ metros- la escasa medida de la montea $-0,83$ metros - haría imposible la visión en los extremos de la cimbra. Y esto sin considerar el obstáculo añadido de la obligada barandilla.

93 En el patio de la Olivera de Valencia el corredor de las mujeres también se encontraba entre la segunda galería y el tejado.

94 Si fuera así, esa parte carecería de aposentos o, si los tenía, no se podrían utilizar cuando el montaje de la obra exigiera apariencias o ventanas. 
ese lienzo interno y al nivel de la cazuela, se encontrara el «desván de los tornos» 95 .

El teatro, como el de la Olivera de Valencia, el de Zamora, el de las Arcas de Lisboa o el Coliseo de Sevilla, estaba techado en toda su superficie. El apartado décimo del contrato de obra establece «que todo el cuerpo del patio, y encima de las bóvedas y cazuela, ha de quedar cubierto», pero del procedimiento utilizado tan sólo se detalla «que la maderación para cubrir los tejados ha de ser de grueso suficiente, $y$ ha de estar uno de otro media vara, y su techo ha de ser todo de tabla de chilla sin labrar, brutas como ellas vienen, que queden a tope (...), con su tejado con las vertientes que se requiere». La aplicación de estos requisitos a un edificio levantado según los planos del proyecto, exigía en aquella época una armadura en caballete con albanegas atirantadas de entrecintas o tornapuntas y con las soleras apoyadas en los extremos de las pilastras, muros y contrafuertes. Es muy posible que dicho forjado estuviera a la vista, y que el techo chillado de que nos habla el contrato no fuera un tosco cielo raso fijado en ochaveros, sino la tablazón necesaria para recibir las tejas. En cuanto a las vertientes opinamos que la crujía de entrada la tenía a un agua y el resto de la fábrica a cuatro.

La iluminación del local, lo mismo que en casi todos los teatros cubiertos, procedería de doble fuente: la artificial de las bujías, velones y reverberos, y la natural de las once ventanas abiertas en los muros de la galería baja ${ }^{96}$. Es presumible que el tejado contara con varias claraboyas las cuales, a más de proporcionar luz cenital, sirvieran también de chimeneas para la evacuación de humos y la ventilación de la sala.

Ignoramos la ubicación exacta del escenario, al igual que su amplitud y altura, pero, por la costumbre castellana de situarlo frente a la cazuela ${ }^{97}$, debería de encontrarse en el fondo derecho del patio, conjetura ésta que parece acreditar el detalle comentado de que desde el vestíbulo no existiera por esa mano ninguna entrada a la platea. Por la madera consumida en fabricar el pódium,

95 «En la gran mayoría de las obras teatrales es el primer balcón el que se utiliza, pero el segundo se usa sobre todo para las tramoyas de comedias de espectáculo» (J. E. VAREY, op. cit., p. 227).

96 Sus medidas eran de $125 \mathrm{cms}$. de ancho por $63 \mathrm{cms}$. de alto. En el alzado no se señalan en el corredor superior. Jose María RuANo dE LA HAZA recoge en *Actores, decorados y accesorios escénicos» el testimonio de Luis Vélez de Guevara de que en la Olivera de Valencia, antes de recitar la loa, se alumbraba el escenario con hachas o antorchas de cera (Actor y técnica de representación del Teatro Clásico Español, Londres, 1989, p. 91).

97 OTHÓN ARRónlz, op. cit., p. 85. 
156 tablones $^{98}$, pensamos que sería bastante espacioso, y que por hallarse sentados los espectadores su cota no sobrepasaría en mucho el metro y medio ${ }^{99}$ - tampoco bajaría de esa medida para facilitar el paso oculto de los actores a los escotillones-. Lo que sí es seguro, se hallara donde estuviere, es que la estructura de la fábrica hacía innecesario ese murallón de fondo con tres puertas permanentes que se dice tenía en los corrales ${ }^{100}$.

Tampoco conocemos, ni sospechamos, el emplazamiento de dependencias tan genéricas y necesarias como fueron la contaduría, el guardarropa y la guardarropía, la alojería, etc.

La superficie útil del corral permitía un aforo aproximado de 358 personas: 250 acomodadas en el patio, 60 en los aposentos privados, 30 en la cazuela y 18 en la tribuna del Concejo ${ }^{101}$.

A principios del siglo XVIII la Guerra de Sucesión al trono de España hizo de la frontera hispano-portuguesa una zona de abundosa presencia militar y violentos combates. A partir de marzo de 1704 la guarnición de Badajoz se refuerza con nuevos contingentes, y la escasez de alojamientos para tanta tropa obliga a habilitar el patio de comedias como albergue provisional para una compañía del regimiento de Nápoles ${ }^{102}$. Concluida la contienda en 1713 con la llamada Paz de Utrecht, descendió considerablemente el presidio de la plaza $^{103}$, y en 1730 , disponibles ya los tres nuevos cuarteles del Castillo, se desafecta el corral para revertir en sus propietarios. Pero tras veintisiete años de expolio, alterada su primitiva estructura para adaptarla a tan diferente uso y descuidado el mantenimiento de la fábrica, el edificio presentaba señales evidentes de ruina inmediata. El maestro sangrador José de Sagre, que a diario te-

98 La longitud del tablón era de nueve pies, o sea de dos metros y medio. Sin datos documentales es imposible precisar las dimensiones del escenario, ni siquiera por aproximación a las que tuvieron otros teatros dada la disparidad probada de sus dimensiones: El tablado del corral de la Cruz medía 7,5 por 4,2 metros con una superficie 31,5 metros cuadrados, el del Príncipe 8,4 por 5,6 metros con una superficie de 47 metros cuadrados (OTHÓN ARRONIZ, op. cit., pp. 67 y 79) y el de Córdoba 5 por 5,8 metros con una superficie de 29 metros cuadrados (Angel M. GaRCía GómEZ, op. cit., p. 36).

99 Esa era la altura que tenía el del patio valenciano de la Olivera.

$100 \mathrm{~J}$. E. VAREY sostiene que esa fachada del teatro con tres huecos eran «casi con certeza entradas con cortinas en lugar de puertas de madera» (op. cit. pp. 30, 249 y 324).

101 El patio de la Olivera de Valencia tenía una cabida de 372 espectadores sentados en sillas (OTHÓN ARRóniz, op. cit., lámina 4).

102 Por ser el teatro un bien vinculado a obras pías, y por tanto de titularidad eclesiástica, fue el obispo don Juan Marín de Rodezno quien autorizó ese empleo. También se utilizó como vivaque el convento de los dominicos ( $A H P B$, prt. 487, fs. 88 y 90 ).

103 En 1732 la guamición de la ciudad era de doce compañías ( $A M B$, Libro de acuerdos del año 1732 , f. 24 vto.). 
nía que caminar por ante su fachada, declara en un auto judicial «que se persigna y encomienda a Dios cada vez que pasa por aquella calle, por parecerle se le ha de caer encima al reparar que la pared arroja de sí una muy grande barriga no segura», y muy parecidas eran las prevenciones del escribano Juan Alavego y las de algunos vecinos de la manzana ${ }^{104}$. Como el desmoronamiento del edificio era palpable, el peligro para los viandantes ostensible y la propuesta de rehabilitación reprobada por muy costosa, los hospitales, luego de enconadas disputas por motivos económicos, cisma que zanjó una providencia apostólica del 18 de julio de 1732, acuerdan su demolición y levantar en el solar dos casas de vivienda ${ }^{105}$. Cinco meses después una cuadrilla de setenta y cinco operarios arrasó en nueve días uno de los teatros más bellos de la España del Siglo de Oro ${ }^{106}$.

Si el episodio bélico que hemos indicado, y que desvirtuó el uso del local, no se hubiera producido, es seguro que la actividad teatral hubiera proporcionado pingües beneficios a las mandas pías, y de ello tenemos pruebas documentales. En el citado libro de caja del hospital de la Vera Cruz, único que se conserva, aparece sentado el líquido que percibió esa institución durante dos temporadas $^{107}$ : En la de 1672-1673 fueron 1.609 reales y 2.221 en la de 1675 1676 , lo que, corregida la proporcionalidad del reparto, supone un arqueo global de 4.827 y 6.665 reales netos para cada uno de dichos períodos. El rendimiento íntegro es difícil de calcular, aunque podemos conjeturarlo sabiendo que los gastos ordinarios de mantenimiento y explotación rondaban los $182 \mathrm{du}$ cados anuales ${ }^{108}$. Dichas precisiones contables revelan por una parte la masiva asistencia de público a los espectáculos, y por otra la frecuencia de las representaciones.

El primer supuesto, el de la concurrencia, lo acredita el provecho que sacaban los hospitales del importe de las entradas. Veámoslo: El precio de cada

104 Fernando CASTÓN DURÁN, op. cit., p. 160.

105 En 1764 hacía ya años que el hospital de la Vera Cruz habra construido la suya en la mitad del solar. La otra mitad, propiedad conjunta de los hospitales de la Piedad y de la Concepción, la tomo a censo redimible don Francisco Castelar el 2 de febrero de 1764 para edificar en ella su domicilio. Las cantidades pactadas fueron de 5.540 reales de principal con rédito anual de 167 reales (AHPB, Registro de contaduría de hipotecas, leg. 12, f. 17).

106 Fernando Castón DURÁn, op. cit., p. 161.

107 Estos períodos, al menos a efectos comerciales, iban desde el día 1 de mayo de un año hasta el 30 de abril del año siguiente ( $A D P B, 1 \mathrm{lg}$. 19, libro de cuentas, fs. 81 y 85).

108 En 1677 este desembolso se elev6́ a 2.309 reales ( $A D P B$, $1 \mathrm{~g}$. 19, libro de cuentas, f. 140, $A H P B$, prt. 363 , s.f., 12 de julio 1679 , y prt. 1680 , s. f., 6 de mayo, 1680). Ignoramos el detalle de los gastos, pero la subvención por ayuda de costa que se entregaba a las compañías fue siempre de 500 reales. 
una era de seis cuartos, 24 maravedises ${ }^{109}$, de los que sólo un cuarto, 4 maravedises, iba en ventaja de los promotores - de los otros cinco se lucraban las compañías ${ }^{110}$. Si estimamos en 6.746 reales el promedio de los ingresos brutos que percibieron de anata los hospitales ${ }^{111}$, su equivalencia en 229.364 maravedises correspondería al sumando de las aportaciones de 57.341 espectadores a lo largo de la temporada ${ }^{112}$. Esta afluencia pudiera parecer desorbitada si tomamos como única referencia el censo de 6.500 vecinos que por entonces tenía la ciudad ${ }^{113}$, y esto a pesar de su arraigado gusto por el teatro ${ }^{114}$, pero es

109 La entrada no era cara. Para poder valorarla en su tiempo anotamos el precio que tenían en Badajoz algunos productos de primera necesidad: la libra de pan, 6 cuartos; la libra de carne de cordero o de vaca, 12 cuartos; la libra de carne de oveja o de cerdo, 14 cuartos; la libra de tocino fresco, 14 cuartos; la libra de manteca, 19 cuartos; el cuartillo de vino blanco, 5 cuartos; el cuartillo de vino tinto, 3 cuartos; la libra de carbón vegetal, 10 cuartos; la carga de leña portada en bestia menor, 25 cuartos; la libra de jabon, 5 cuartos (una libra equivale a 460 gramos y un cuartillo a medio litro). Por otra parte el importe de 24 maravedises se mantenía inalterado desde antiguo: J. M. DIEZ BORQUE sostiene que esa cantidad se fijo en 1608 para los corrales de Madrid (Sociedad y teatro en la España de Lope de Vega, Barcelona, 1978, p. 143, y El teatro en el Siglo XVII, Madrid, 1988, p. 24); en Carmona, y en 1617, se cobraba «veinte y cuatro maravedís, que es lo que se acostumbra* (Piedad Bolaños y Mercedes DE LOS REYES, «Reconstrucción de la vida teatral de los pueblos de Sevilla», en Teatros y vida teatral, op. cit., p. 164).

${ }^{110} A H P B$, prt. 331 , f. 363 ; prt. 363 , s.f. (12 de julio 1679) y prt. 1680 , s.f. (6 de mayo, 1680 ).

111 Con los datos numéricos parciales que aportamos, la media exacta serfa de 7.746 reales, pero de esa cantidad hemos detraido los 1.000 reales que calculamos como ingreso aproximado por el arriendo de las tribunas - los abonos fluctuaban entre 100 y 150 reales anuales $\left(A C B\right.$, l.a. n. ${ }^{2} 19$, s.f., 9 de julio 1687 y 6 de julio 1689, y l.a. n. ${ }^{9} 20$. s.f., 5 de octubre 1695)-, y que, incluidos en los beneficios de los hospitales como rendimientos fijos, no consta que su aplicación tambien incidiera en provecho de las compañías. En 1603 la ganancia que obtuvo el cabildo de Córdoba por la explotación de su teatro fue de $\mathbf{8 . 8 0 0}$ reales, y de este local sí que sabemos que los espectadores de palcos no abonaban cantidad alguna a los cobradores de las compañías (Angel M. GARCía GómeZ, op. cit., pp. 40 y 53). El importe anual del arriendo de los palcos altos del Patio de la Misericordia de Segovia fue de 160 reales (Mariano GraU, op. cit., p. 15). La cuota establecida para los de Madrid no es parangonable por su elevada cuantía, 2.200 reales en 1636 (J. M. DiEZ BORQUE, op. cit., Sociedad y teatro, p. 154), debida, en nuestra opinión, para preservar de contaminación social a determinadas minorías elitistas.

112 Posiblemente unas 28.000 en 1672-1673, y 43.000 en 1675-1676.

113 Para cortes estadísticos de población en esa época, vid. Fernando Marcos Alvarez, «Badajoz y el tráfico indiano en el siglo XVII», en Revista de Estudios Extremeños, t. XLIII, n. 3 , Badajoz, 1992, pp. 112 y 113.

114 Tenemos recogida mucha documentación con actuaciones de las mejores compañ́as de la escena española del siglo XVII. No olvidemos que Badajoz era localidad de paso y estancia en la ruta Madrid-Lisboa que seguían los comediantes, por lo que las fáciles y frecuentes representaciones educaron el gusto de la población. Como muestra significativa de esta afición generalizada por el teatro tenemos la taxativa prohibición que recogía las constituciones del recién creado Seminario Diocesano (1664) de que los colegiales presenciaran las comedias por el perjuicio que eso acarrea- 
que la población de hecho era mucho más numerosa: sólo la gente de guerra del Real Ejército de Extremadura acuartelada en la ciudad y próximos alrededores superaba los 3.000 hombres, y es seguro que entre los militares también hubo buenos y perseverantes aficionados ${ }^{115}$. Es una lástima que no dispongamos de más datos cuantificados ${ }^{116}$, de ahí la restringida validez cronológica de las anteriores conclusiones, pero hay otros relatos que nos permiten extender estas inferencias exitosas a tiempos distintos en la vida del local. El 12 de enero de 1673 los comisarios del Corpus contratan las comedias y auto de esa festividad con la compañía de Miguel de Orozco e Hipólito de Olmedo, y en el compromiso notarial ${ }^{117}$ se incluye esta cláusula: «Y es condición que a los dichos representantes no se les ha de obligar a que dejen de hacer representaciones en cualquier día en el corral de comedias, excepto los días señalados para las dichas representaciones [las públicas en honor del Santísimo], porque en ellos no han de poder representar en parte alguna». Parecidas restricciones se leen en los convenios que firmaron dichos delegados con la compañía de Carlos de Salazar ${ }^{118}$ el 14 de abril de 1674, con la de Pablo Martín de Morales $^{119}$ el 22 de abril de 1679 y con la de Jacinto Rico ${ }^{120}$ el 6 de mayo de 1680. No creemos que ese requisito lo demandara el respeto con que se guardaba la conmemoración religiosa, - los festejos del Corpus nunca se caracterizaron por su recogida y estimulante contemplación, sino más bien por el alboroto popular y regocijo profano ${ }^{121}$ - , sino por la posibilidad de que muchos vecinos, tras asistir al espectáculo matinal y gratuito del auto, se hurtaran de la procesión eucarística y demás oficios litúrgicos, que tan tarde concluían, para divertirse con la obra que pudiera hacerse en el corral. Es cierto que lo que acabamos de exponer no puede documentarse, pero parece confirmarlo un testimonio muy cercano referido a una situación semejante: Era costumbre repre-

ba a su recta formación eclesiástica, prohibición que no se hubiera contemplado de no haber existido ese peligroso ambiente favorable al teatro.

115 Confirma este supuesto la Real Orden del 13 de enero de 1692 que regulaba la entrada de los soldados en los corrales de comedias.

116 Los motivos de esta carencia ya quedaron comentados con anterioridad.

$117 A H P B$, prt. 361, s.f. (12 de enero, 1673).

$118 A H P B$, prt. 361 , s.f. (14 de abril, 1674).

$119 A H P B$, prt. 363 , s.f. (22 de abril, 1679).

$120 A H P B$, prt. 1680 , s.f. (6 de mayo, 1680).

121 Ya en 1583, en las actas del sínodo diocesano convocado por el obispo don Diego Gómez de Lamadrid, se lee esta queja: «por experiencia se ha visto que por hacerse la procesión tan tarde y haber visto ya las representaciones, las más de las gentes se iban a sus casas a comer, y otras, tras las representaciones y danzas, dejando ir acompañando el Sacramento». Para el siglo XVII, vid. quejas parecidas en Fernando MARCos ALVAREZ, «La polémica de los autos sacramentales en Badajoz", en Campo Abierto, n. ${ }^{\circ} 5$, Badajoz, 1988, pp. 32-45. 
sentar en la octava del Corpus una comedia de santos en la plazuela de la iglesia de Santa María del Castillo; pues bien, los comisarios de 1674 ruegan al Ayuntamiento $^{122}$ que en la tarde de ese día «no se dé lugar a que haya función en el patio de comedias porque la gente asista a la de la iglesia que es más decente». El que la clausura transitoria del corral garantizara la presencia de público en festejos tan señalados, es prueba de la atracción que ejercía sobre la sociedad pacense el teatro comercial y de la habitual abundancia de espectadores.

Respecto al segundo supuesto, la frecuencia de las representaciones, no son muchos los datos que tenemos sobre las compañías que actuaron en el patio y del tiempo que mantuvieron su cartel. Sabemos que la de Jerónimo de Heredia inauguró el teatro en agosto de 1671 con cuarenta funciones ${ }^{123}$, y que el 12 de julio de 1679 se contrató a la de Pablo Martín de Morales ${ }^{124}$ para que a partir del 25 de diciembre escenificara treinta farsas - dieciséis tenían que ser «nuevas y diferentes de las que han representado en esta ciudad»- También conocemos que las compañías que hacían los festejos del Corpus prolongaban su estancia en la ciudad por el trabajo añadido que les proporcionaban los hospitales. Esta seguridad de incrementar considerablemente sus ganancias era el incentivo que utilizaba la catedral y el municipio para conseguir comediantes que les garantizaran las representaciones del Corpus y su octavario, oferta, y señuelo, que siempre fue consentida por las mandas pías porque así se liberaban ellas del engorroso trámite de buscar quienes les hicieran las "vacaciones de San Juan y de la Asunción», y sus mayordomos de abonar gastos de viaje ${ }^{125}$. Aprovechando estos conciertos vinieron en 1673 la compañía de Miguel de Orozco e Hipólito de Olmedo, en 1674 la de Carlos de Salazar ${ }^{126}$, en 1679 la de Pablo Martín de Morales y en 1680 la de Jacinto Rico ${ }^{127}$.

La guerra de independencia de Portugal aminoró a partir de 1640 la presencia de cómicos castellanos en la ciudad de Lisboa, hasta entonces muy abundante, $y$ en consecuencia su trasiego por Badajoz en ruta hacia ese destino o en retorno a la corte. La contratación de compañías se hizo desde esa fecha muy dificultosa y cara, por ello no es de extrañar que algunos años, parece ser

$122 A C B$, l.a. n. ${ }^{9} 15$, s.f. (18 de mayo 1674).

$123 A H P B$, prt. 331, f. 363.

$124 A H P B$, prt. 363, s.f. (12 de julio 1679).

$125 A H P B$, prt. 361, f. 135.

126 Hizo treinta funciones ( $A H P B$, prt. 361, s.f., 14 de abril 1674).

127 A partir del 25 de mayo haría cuarenta representaciones. El contrato se firmo el 6 de mayo de 1680 (AHPB, prt. 1680, s.f., 6 de mayo 1680). 
que pocos, no hubiera comedias. En 1685 el cabildo catedralicio condiciona el libramiento de los 150 reales que abonaba por su palco sólo a los años en que hubiera funciones, y ese año acuerda no entregar a los hospitales cuota algu$\mathrm{na}^{128}$, pero sí tuvo que hacerlo en 1689 y 1695 , señal evidente de que las hubo en las temporadas inmediatas ${ }^{129}$. Una cita tardía, también de la catedral, denuncia con llaneza esos vacíos: El 8 de enero de 1698 los capitulares ${ }^{130}$ deciden que «se compongan las barandillas de los balcones de las comedias, y que se asista a ellas habiéndolas». Después de este dato la carencia de información sobre representaciones en el corral es para nosotros absoluta ${ }^{131}$, aunque por noticias marginales sospechamos que en 1699 actuó la compañía de José de Prado ${ }^{132}$ cuando, en el mes de abril, pasó por Badajoz hacia el Puerto de Santa María.

$128 A C B$, l.a. n..$^{9} 18$, s.f. (18 de julio 1685) y l.a. n.. 19 , s.f. (9 de julio 1687),

$129 A C B$, l.a. n. ${ }^{9} 19$, s.f. (6 de julio 1689) y l.a. n. ${ }^{2} 21$, s.f. (8 de enero 1698 ).

130 En 1695 rebajó unilateralmente la catedral el importe de su abono a 100 reales anuales para igualarlo a lo que pagaban otros arrendatarios.

131 No nos extraña la carencia de noticias sobre las acostumbradas representaciones posteriores al Corpus. Pensamos que hubo pocas, si las hubo, pues el obispo don Juan Marín de Rodezno había conseguido erradicar por completo los festejos de ese día (Fernando MARcos AlvareZ, $o p$. cit., «La polémica de los autos sacramentales»).

132 Es un contrato con arrieros para la conducción de la compañáa y su equipaje ( $A H P B$, prt. 421 , s.f., 15 de abril 1699). 


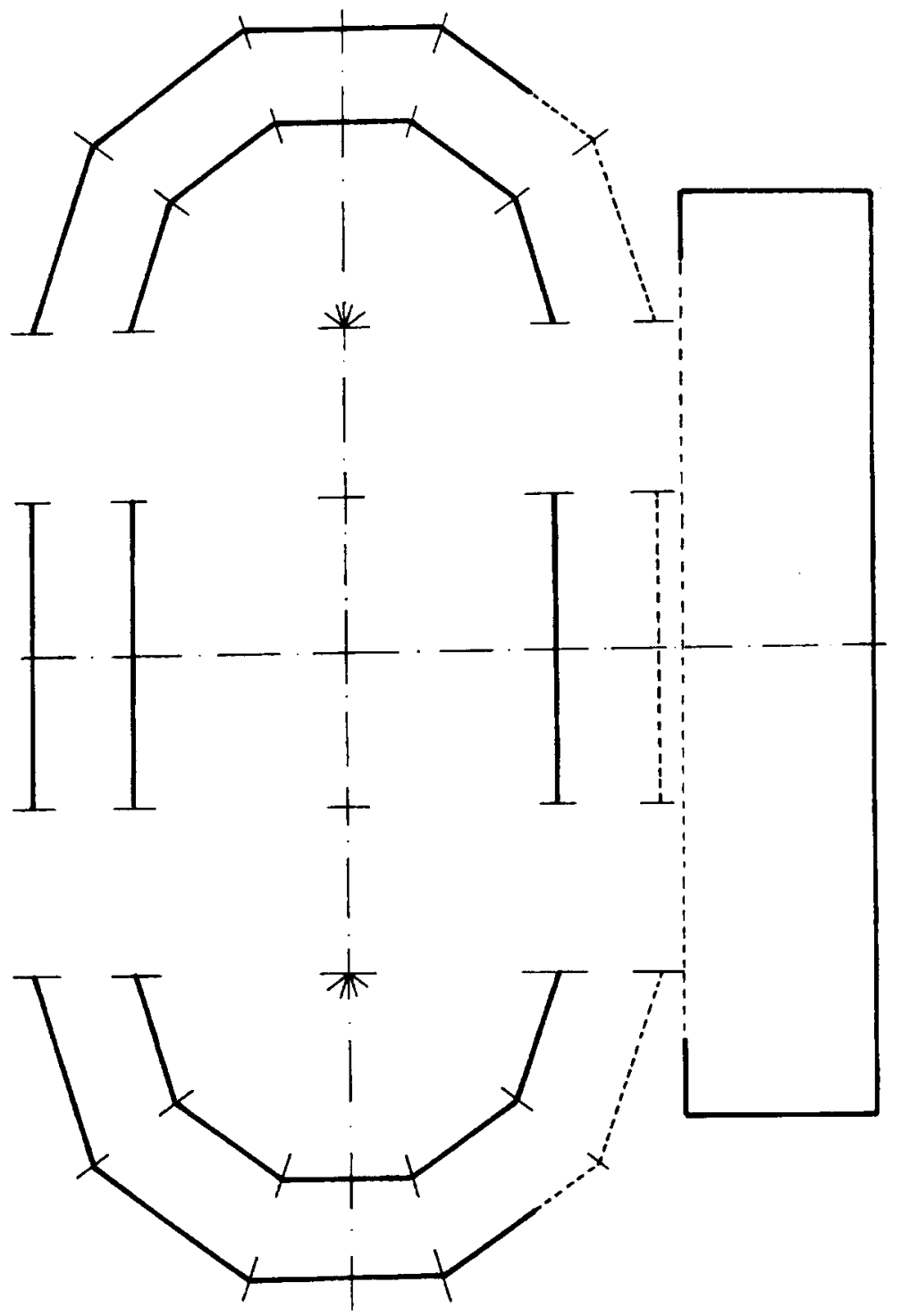

LÁMINA 1 


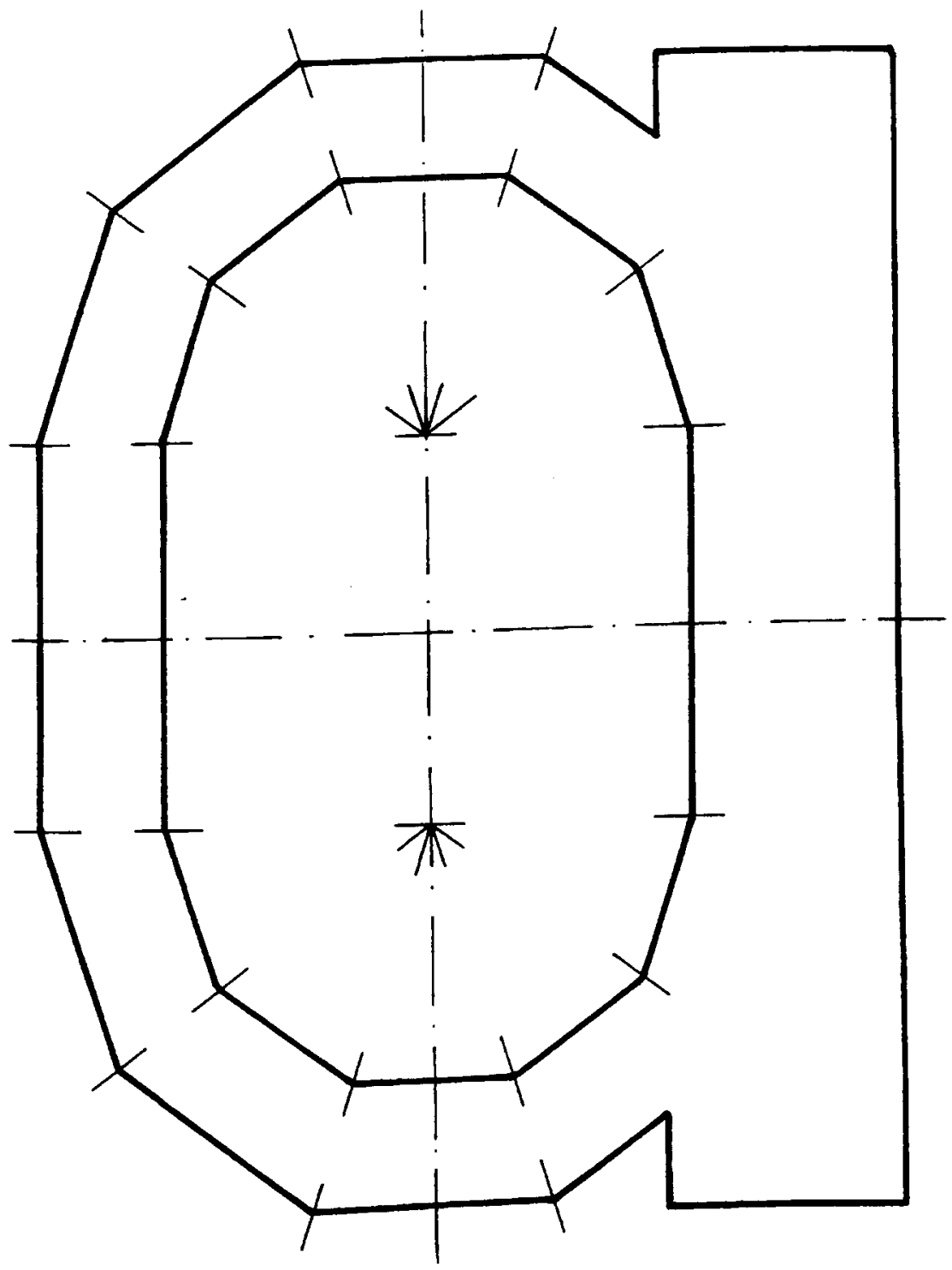

LÁMINA 2 


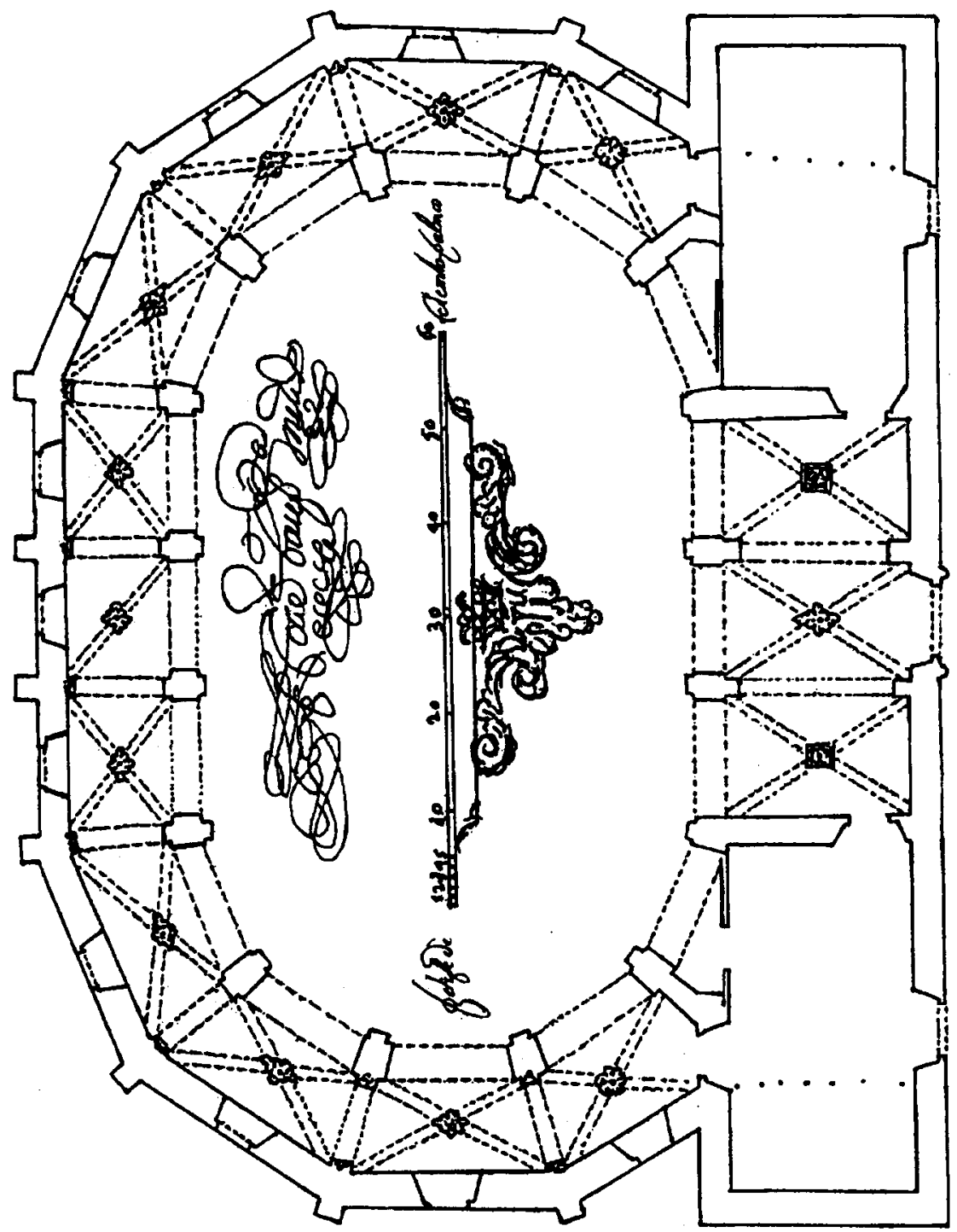

LÁMINA 3 


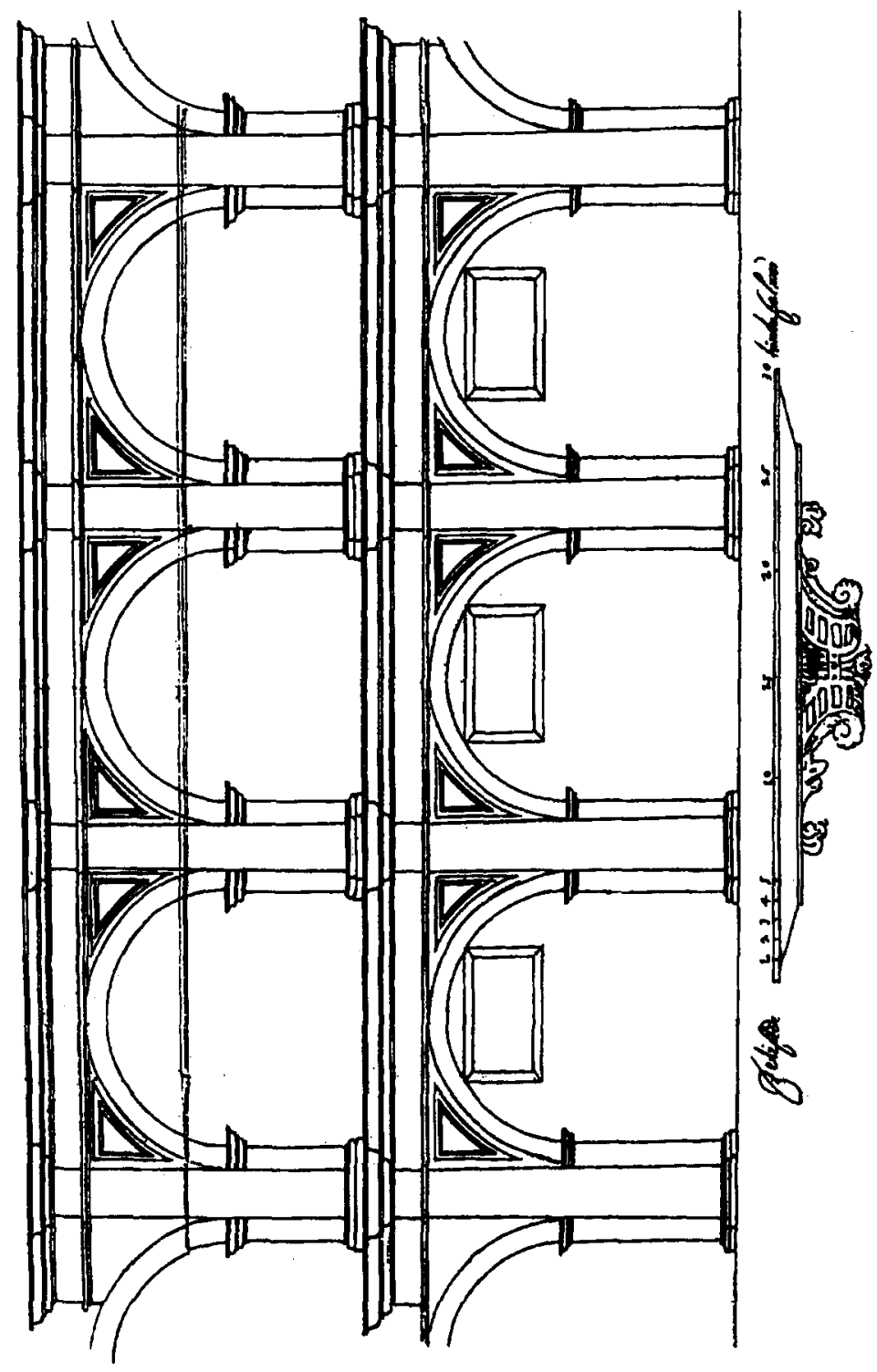

LÁMINA 4 